\title{
Correction to: Fractures in Sport
}

Greg A. J. Robertson and Nicola Maffulli

\section{Correction to: G. A. J. Robertson, N. Maffulli (eds.), Fractures in Sport,} https://doi.org/10.1007/978-3-030-72036-0

This book was inadvertently a spelling error in 2nd editor's surname. The correct name is Nicola Maffulli, this has been updated with this erratum. 